\title{
Additive Manufacturing of Cemented Tungsten Carbide with a Cobalt-Free Alloy Binder by Selective Laser Melting for High-Hardness Applications
}

\author{
NICHOLAS KU ®i], ${ }^{1,2}$ JOHN J. PITTARI III ${ }^{10,3}$, STEVEN KILCZEWSKI, ${ }^{1,4}$ \\ and ANDELLE KUDZAL ${ }^{1,5}$ \\ 1.-CCDC Army Research Laboratory, Aberdeen Proving Ground, Aberdeen, MD 21005, USA. \\ 2.—e-mail: nicholas.ku.civ@mail.mil. 3.—e-mail: john.j.pittari2.civ@mail.mil. 4.—e-mail: \\ steven.m.kilczewski.civ@mail.mil.5._e-mail: andelle.d.kudzal.civ@mail.mil
}

Cemented tungsten carbide (WC) is commonly used for wear-resistant applications, such as cutting tools and abrasives due to its extremely high hardness. This hardness leads to post-process machining of WC to be time- and cost-intensive. This study examined the feasibility of additive manufacturing of cemented WC to near-net-shape in an effort to reduce post-process machining. The binder phase in the manufactured samples is an iron-based alloy, which has a lower melting temperature than cobalt, the conventional binder in cemented WC. In this proof-of-concept study, cuboid specimens of WC with a low content of the iron-based alloy binder were printed; the effect of different processing conditions on the resultant density and microstructure of the material were investigated. Theoretical densities as high as $95 \%$ were achieved using this method. Artifacts indicative of the manufacturing process are present in the samples, and the challenges in removing the processing history from the final microstructure are discussed.

\section{INTRODUCTION}

The properties of cemented tungsten carbide (WC) are superior for many applications, with the material possessing high hardness, density, flexural strength, and fracture toughness. ${ }^{1}$ Such applications include cutting tools, abrasives, and armorpiercing projectiles. These same properties, which make WC beneficial for wear-resistant applications, render the material difficult to employ for traditional subtractive processing, as the machining of the material is very time- and cost-intensive. Furthermore, new application-driven demands have led to parts with increasingly complex shapes, which further compounds machining difficulties. For these reasons, there has been an increase in studies of the near-net-shape manufacturing of cemented WC parts. Previous work has been conducted using various additive manufacturing (AM) methods, such as 3D gel-printing ${ }^{2}$ and binder jetting, ${ }^{3}$ but these methods require two separate steps: material printing and subsequent ceramic densification.
Powder bed fusion processes for AM provide a distinct advantage to print and densify the material in a single step, reducing the manufacturing time. One such single-step process is selective laser melting (SLM), where a laser provides the thermal source to induce fusion between powder particles. ${ }^{4}$ Cemented WC materials are ideal for SLM processing due to the lower melting temperature of the binder phase compared to the melting temperature of WC $\left(2870^{\circ} \mathrm{C}\right) .^{5}$ The most common WC binder materials are cobalt $(\mathrm{Co})$, iron $(\mathrm{Fe})$, and nickel $(\mathrm{Ni})$, which have melting temperatures of $1495^{\circ} \mathrm{C}$, $1535^{\circ} \mathrm{C}$, and $1455^{\circ} \mathrm{C}$, respectively. ${ }^{5}$ The binder phases melt readily in the SLM process, allowing the binder phase to wet and fuse the WC grains together.

SLM of cemented WC has been conducted with varying amounts of success in previous work. Kumar processed WC-Co parts with SLM, yet the samples were highly porous, and infiltration with bronze was necessary to reach a final relative density of $96 \%{ }^{6}$ Ulmann et al. ${ }^{7}$ investigated a wide range of laser parameters and found that higher 
intensities led to thermal cracking while lower intensities yielded residual porosity in the printed WC-Co samples. Furthermore, a relatively high binder content (17 wt.\%) was used to promote increased amounts of binder material between the WC particles, which is detrimental to the overall mechanical properties of the final product. Enneti et al. conducted a similar study with WC-Co at 12 wt.\%, but was challenged with excessive vaporization of the Co binder, leading to low residual levels Co (3 wt.\%). Furthermore, Enneti et al. observed large, uncontrolled, columnar grain growth in the sample. ${ }^{8} \mathrm{Li}$ et al. ${ }^{9}$ printed WC material using 8.3 wt.\% Ni binder, and very high laser power, which ultimately heated the sample above the WC melting temperature $\left(\approx 2870^{\circ} \mathrm{C}\right)$ and decomposed some of the WC into $\mathrm{W}_{2} \mathrm{C}$.

In an effort to overcome processing challenges associated with SLM of cemented WC materials, creative solutions have been investigated. Cavaleiro et al. ${ }^{10}$ sputtered a coating of stainless steel onto the WC particles to promote better mixing of the powder and binder phases, but the resultant samples still had high residual porosity, due to the poor wetting of WC by steel. However, the coating of particles is generally an effective way to promote better absorption of laser energy by the binder phase, in turn leading to more effective fusion of the particles. ${ }^{4}$ In a separate investigation, Kumar utilized a post-process heat treatment of his samples after printing and found an improvement in the mechanical properties. ${ }^{11}$

Previous work in SLM of cemented WC all utilized WC powder with particle sizes ranging from several microns to tens of microns. ${ }^{6,8,10,11}$ The hardness of WC generally follows a Hall-Petch-like relationship, in which a finer grain size yields a higher hardness of the material. ${ }^{12}$ Therefore, it is important to start with the finest particle size of WC in order to minimize the grain size and maximize the hardness of the final part.

Conversely, fine particles exhibit poor flowability, which can lead to ineffective powder delivery during the relayering process and produce poorly packed powder beds with a high porosity. ${ }^{4}$ Many commercial SLM instruments utilize a hopper design for delivery of powder. Flow behavior of powder out of a hopper system is best characterized using an annular shear cell to measure the unconfined yield stress (UYS) as a function of the major principal stress (MPS) applied. The ratio of MPS to UYS is known as the flow function of a powder, which is a commonly used and well-established metric to measure the powder flowability. A qualitative table showing the values of flow function for varying degrees of flowability is shown in Table I. ${ }^{13,14}$

The most common binder material for $\mathrm{WC}$ is $\mathrm{Co}$, due to its superior wetting behavior with WC, but it possesses both health- ${ }^{15}$ and economic-related ${ }^{16}$ disadvantages. An iron-nickel-zirconium (Fe-Ni-Zr) alloy is a superior binder material to Co, providing high density and mechanical performance, while
Table I. Flowability assessment of powders

\begin{tabular}{lc}
\hline Flow function & Evaluation \\
$>10$ & Free flowing \\
$4-10$ & Easy flowing \\
$2-4$ & Cohesive \\
$1-2$ & Very cohesive \\
$<2$ & Not flowing \\
\hline
\end{tabular}

being environmentally friendly. ${ }^{17,18}$ The effectiveness of the binder is illustrated by a comparison of the Knoop hardness values for the traditionally processed, dense samples, with WC-FeNiZr and WC-Co samples having values of $15.9 \mathrm{GPa}$ and $12.9 \mathrm{GPa}$, respectively. ${ }^{17}$ In practical applications of SLM of these materials, the Fe-Ni-Zr metal alloy binder has several processing advantages over Co. The alloy melts at $1435^{\circ} \mathrm{C},{ }^{17}$ which is a lower temperature than pure Co and therefore more amenable to a process that is dependent on binder melting for powder bed fusion . Ni and $\mathrm{Zr}$ also have higher boiling temperatures than $\mathrm{Co},{ }^{5}$ which increases the temperature to which the powder bed can be heated before potentially vaporizing the binder from the cemented carbide system. As the thermal energy heating the powder bed is derived from the laser energy density, the higher boiling temperature of the binder constituents allows for a greater design space of the laser parameters. This study investigates the feasibility of SLM of a submicron WC powder with a Fe-Ni-Zr metal alloy binder.

\section{EXPERIMENTAL PROCEDURES}

\section{Materials}

A powder mixture consisting of $90 \mathrm{wt} \% \mathrm{WC}$ powder and 10 wt.\% Fe-Ni-Zr metal alloy binder was selected for investigation. The WC powder used in this study was the SC04U variant from Global Tungsten \& Powders (Towanda, PA, USA), with a Fisher sub-sieve sizer particle size of less than $0.70 \mu \mathrm{m}$. The Fe-Ni-Zr composition is produced inhouse by mechanical alloying. The resultant powder is on average $10 \mu \mathrm{m}$ in diameter with a nanoscalegrain substructure. ${ }^{18}$

The Fe-Ni-Zr binder powder was distributed throughout the WC powder using a ball-milling technique. The milling parameters were such that the process was designed to be more of a mechanical mixing/distribution method rather than a grainrefinement exercise. Nickel-bonded WC satellites (6\% nickel by weight) of $3 / 16^{\prime \prime}($ c. $4.7 \mathrm{~mm}$ ) size were employed as the milling media in a $\approx 8: 1$ ratio of media to powder (i.e., $800 \mathrm{~g}$ of media to $100 \mathrm{~g}$ of WCFeNiZr powder in a mill charge). This charge was placed in a $250-\mathrm{mL}$ high-density polyethylene mill vessel. The mill rack was set to a rotational speed $(\approx 100 \mathrm{rpm})$ sufficient to produce moderate 
impinging of the media on the raw powders with minimal "tossing" of the media to reduce the grainrefinement effect. This mixing procedure was executed for $72 \mathrm{~h}$ to produce a sufficient homogeneous distribution of the binder among the carbide powder. The powder was separated from the media by passing it through a series of sieve screens, the finest of which was 60 mesh $(250 \mu \mathrm{m})$. The relatively low intensity mixing process is anticipated to "smear" the softer binder grains onto the harder WC grains in an effort to create a coated ceramic particle. ${ }^{18}$ A scanning electron microscope (SEM) image of the milled WC-FeNiZr powder is shown in Fig. 1, which highlights the fine particle size and prismatic particle shape.

Use of a coated particle for the SLM process gives two important advantages. First, more direct exposure of the alloy binder to the laser radiation allows for greater energy absorption and, therefore, the most efficient means to create a melt pool. Second, a better dispersion of binder in the powder compact promotes a more effective binding of the WC particles, which subsequently promotes wetting of the WC grains by the binder and limits the creation of large binder pools. ${ }^{4}$

\section{Processing}

The AM process was conducted using a ProX 100 SLM (3D Systems, Rock Hill, SC). The system is equipped with a neodymium-doped ytterbium-aluminum-garnet (Nd:YAG) laser with a wavelength of $1070 \mathrm{~nm}$ and a maximum power output of $100 \mathrm{~W}$. The processing parameters combinations used for each individual sample are listed in Table II. The laser power was varied between 40 and $75 \mathrm{~W}$. The scan speed was set at 150 or $75 \mathrm{~mm} / \mathrm{s}$, and the hatch spacing values that were investigated were 75 and $50 \mu \mathrm{m}$. All samples were cuboid specimens

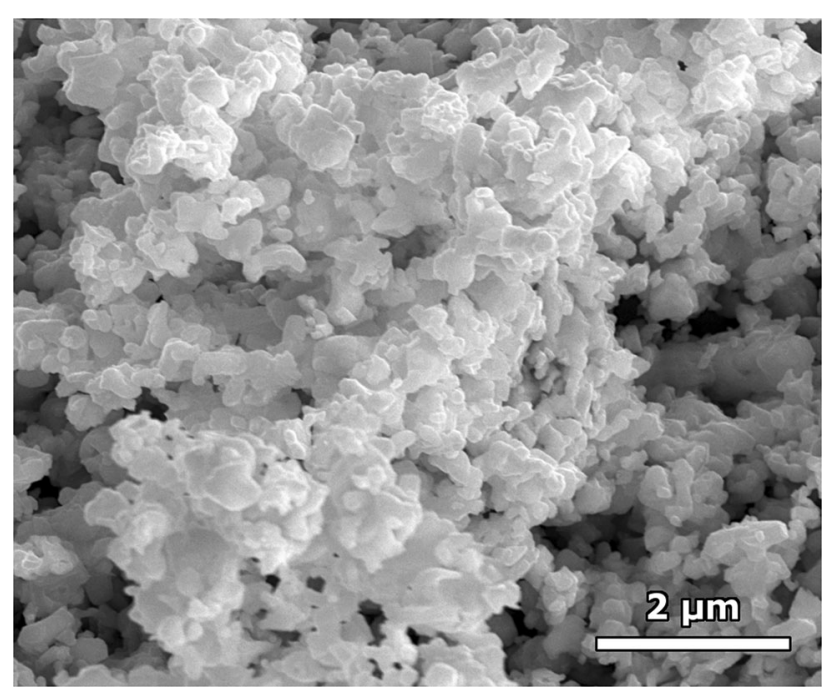

Fig. 1. A SEM image of the submicron WC powder used for SLM processing. manufactured with $5 \mathrm{~mm}$ side dimensions; a layer thickness of $30 \mu \mathrm{m}$ was kept constant for all specimens. All samples were processed under flowing Ar. The corresponding applied areal energy density, or Andrew's Number, $\mathrm{E}_{\mathrm{A}}$, for each specimen was calculated using Eq. 1:

$$
E_{A}=P /(U \times S P)
$$

where $P$ is the laser power, $U$ is the laser scan speed, and $S P$ is the hatch spacing between parallel scan lines. ${ }^{4}$

Samples 7, 8, and 14 were subjected to additional post-processing steps to examine the effect on the sample density. After SLM processing, these three samples were placed in a hot isostatic press (AIP, Columbus, OH, USA). Samples were processed with a ramp rate of $5^{\circ} \mathrm{C} / \mathrm{min}$ to a dwell temperature of $1350^{\circ} \mathrm{C}$ and dwell time of $3 \mathrm{~h}$. The chamber was simultaneously backfilled with ultra-high purity argon gas (99.999\%) until an isostatic pressure of 103.4 MPa was achieved.

\section{Characterization}

The particle size distribution of the powder before processing was measured using a Horiba Partica LA-960 (Kyoto, Japan) laser diffraction particle size analyzer. Flowability of the powder was also measured using a Brookfield PFT Powder Flow Tester (Middleboro, MA, USA). The standard test procedure for annular shear cells was followed for measurement of the flow function of a powder. ${ }^{14}$ The densities of the processed samples were measured using the Archimedes' Principle on an AX205 DeltaRange Analytical Balance (Mettler-Toledo, Columbus, OH, USA), utilizing deionized water as the immersion medium. The theoretical density of each sample was calculated using the estimated theoretical density of the cemented carbide powder blend $\left(14.58 \mathrm{~g} / \mathrm{cm}^{3}\right)$. Microstructural analysis of the samples was conducted by mounting the samples in epoxy and polishing them following standard metallography procedures to expose a cross-section of the specimen. Imaging was conducted using a desktop SEM (Phenom XL, Eindhoven, Netherlands). The chemical composition of each sample was characterized using a Rigaku NEX CG (Tokyo, Japan) x-ray fluorescence (XRF).

\section{RESULTS AND DISCUSSION}

\section{Powder Characterization}

The $\mathrm{d} 10$, d50, and $\mathrm{d} 90$ particle sizes of the powder are $0.67 \mu \mathrm{m}, 1.11 \mu \mathrm{m}$, and $2.21 \mu \mathrm{m}$, respectively, as measured by laser diffraction. To understand the powder flowability, the flow behavior of the blended WC-FeNiZr powder was compared to commercially available EOS Ti64 powder (Krailling, Germany). The EOS Ti64 is a metal $\mathrm{Ti}_{6} \mathrm{Al}_{4} \mathrm{~V}$ powder that is optimized for SLM processing due to its high flowability. While the Ti64 powder offers no bearing 
Table II. The SLM processing parameters investigated

\begin{tabular}{|c|c|c|c|c|}
\hline Sample & Energy density $\left(J / \mathbf{m m}^{2}\right)$ & Power (W) & Speed $(\mathrm{mm} / \mathbf{s})$ & Hatch spacing $(\mu \mathrm{m})$ \\
\hline 1 & 20.00 & 75 & 75 & 50 \\
\hline 2 & 16.00 & 60 & 75 & 50 \\
\hline 3 & 13.33 & 75 & 75 & 75 \\
\hline 4 & 13.33 & 50 & 75 & 50 \\
\hline 5 & 10.67 & 60 & 75 & 75 \\
\hline 6 & 10.00 & 75 & 150 & 50 \\
\hline 7 & 8.89 & 50 & 75 & 75 \\
\hline 8 & 7.11 & 40 & 75 & 75 \\
\hline 9 & 6.67 & 75 & 150 & 75 \\
\hline 10 & 6.67 & 50 & 150 & 50 \\
\hline 11 & 5.33 & 60 & 150 & 75 \\
\hline 12 & 5.33 & 40 & 150 & 50 \\
\hline 13 & 4.44 & 50 & 150 & 75 \\
\hline 14 & 3.56 & 40 & 150 & 75 \\
\hline
\end{tabular}

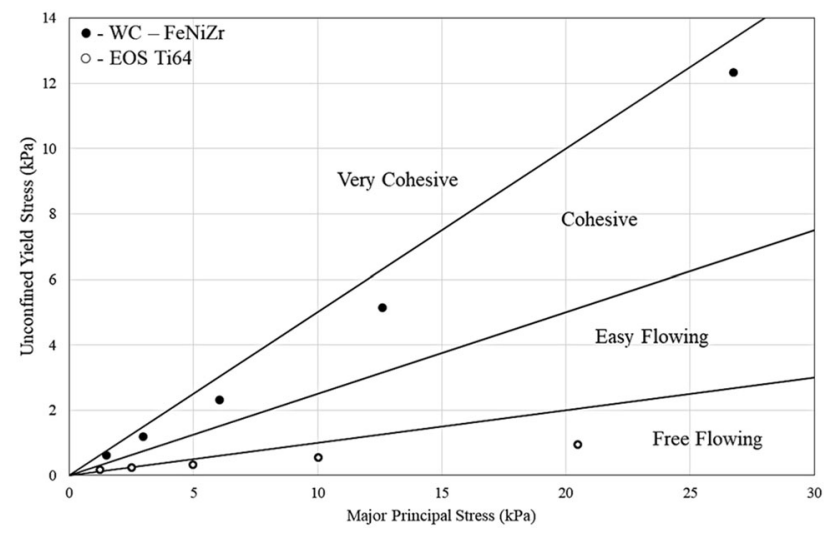

Fig. 2. The UYS of powders used in SLM processing with different flow function regimes shown.

from a material standpoint, it provides insight into the necessary flow behavior of a powder for optimal SLM processing. This behavior is highlighted in Fig. 2, where the UYS of the two powders was measured as a function of the MPS applied. Using the flowability assessment defined in Table I, the different flow function regimes are highlighted in Fig. 2. The WC-FeNiZr has a cohesive flow behavior through all the values of MPS that were measured. Conversely, the EOS powder is free flowing, which is part of the SLM process optimization. The poor flowability of the WC-FeNiZr powder is likely due to the fine particle size and angular particle shape. This can cause poor powder layering during the SLM processing, which can lead to poor powder packing and high porosity.

\section{Sample Densities}

Of the samples listed in Table II, only six $(2,4,7$, 8,11 , and 14) were successfully manufactured into a mechanically stable piece. Samples were considered to be unsuccessful if they did not maintain their structural integrity after manufacturing. Laser power of $75 \mathrm{~W}$ was determined to be too great for this binder system as none of those samples $(1,3,6$, and 9) possessed mechanical integrity, most likely due to binder boiling leaving only the unbound ceramic particles behind. For all of the samples tested in this study, two variables of the process were not investigated, and thus, held constant: (1) the powder layer thickness, and (2) the powder bed temperature. As the powder used in this study was not granulated, in order to increase the flow characteristics, deposition of each layer of powder was erratic. Using a larger layer thickness may aid in a more uniform deposition. This parameter could also help with radiating heat to prevent instances of binder vaporization, which may be evident when processing with higher laser powers.

The measured density of the samples is shown in Table III. Due to the immersion method for the measurement, the density value represents a skeletal density, which excludes open porosity from the sample volume. Therefore, the measured densities are not representative of the bulk sample, but only of the material at a microscale, which still illustrates the ability of the SLM process to locally densify the material. The measured skeletal density of the samples increased with increasing energy density of the prints, with calculated theoretical densities reaching as high as $95 \%$ (sample 2). It is important to note that the theoretical value is dependent upon the as-manufactured sample having the same chemical composition as the constituent powder. Changes in the composition from the SLM process, such as boiling of the metal alloy binder, would alter the theoretical density. Furthermore, as the Archimedes density was measured using immersion in water, open porosity would allow for water to infiltrate into the sample, which would increase the measured bulk density. To better gain a greater understanding of the nature of porosity within the sample, the microstructures of the printed samples were analyzed. 
Table III. The measured Archimedes densities of the down-selected SLM samples

\begin{tabular}{|c|c|c|c|c|}
\hline Sample & Energy density $\left(\mathrm{J} / \mathbf{m m}^{2}\right)$ & Power (W) & Density $(\mathrm{g} / \mathrm{mL})$ & TD (\%) \\
\hline 2 & 16.00 & 60 & 13.85 & 95.0 \\
\hline 4 & 13.33 & 50 & 13.38 & 91.8 \\
\hline 7 & 8.89 & 50 & 13.32 & 91.4 \\
\hline 8 & 7.11 & 40 & 12.96 & 88.9 \\
\hline 11 & 5.33 & 60 & 12.08 & 82.9 \\
\hline 14 & 3.56 & 40 & 11.32 & 77.6 \\
\hline
\end{tabular}

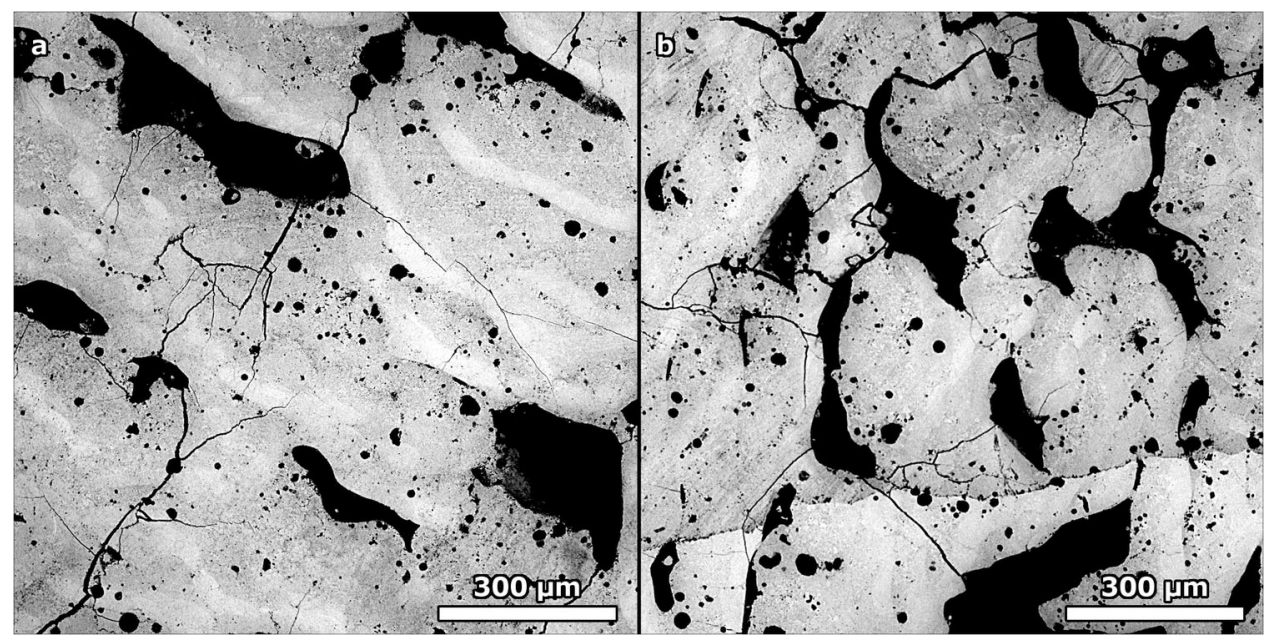

Fig. 3. Cross-section SEM images of (a) sample 2 and (b) sample 4 showing sample porosity.

\section{Microstructures}

Figure 3 shows cross-sectional images for two of the printed samples: 2 and 4. Macro-pores, some as large as $500 \mu \mathrm{m}$, were found throughout the microstructure. Due to the large scale of the porosity, the measured densities of the samples listed in Table III are confirmed as skeletal density measurements and not true bulk densities. The regularity of the porosity suggests that they are related to the discrete powder layers. These macro-pore defects could be corrected by increasing the powder layer thickness from the current layer thickness of $30 \mu \mathrm{m}$, as thicker powders layers may help reduce porosity in future samples. Due to the necessity of the powders flowing during the layering process, the macro-pore defects may also be due to poor flowability of the powder, which is shown in Fig. 2. The submicron size of the WC particles likely compounds the flowability issue. Conducting a granulation step for the milled powder may also help to increase the powder flowability which will lead to improved reproducibility of the layering process and reduction of porosity. Large cracks were seen in the samples, connecting through the large macropores. These cracks are likely due to the thermal stresses generated in the material during cooling. Using lower laser energy densities, as well as a heated powder bed, may help to alleviate these stresses and prevent cracking.

Figure 4 shows SEM images of the microstructure of sample 2 at a higher magnification than seen in Fig. 3a. Highly circular porosity that is roughly several microns in diameter is apparent in Fig. 4a. These pores are indicative of entrapped gas, which again can be attributed to gas within the powder itself, which was trapped due to powder compaction during the layering process. ${ }^{19}$ At the local scale shown in Fig. 4b, there is high contiguity of the ceramic grains within the samples. The voids between the grains are filled with binder material, suggesting good melting of the binder and wetting of the WC grains. Large grains are present, indicating significant grain growth from the starting particle size during the processing, due to the d90 particle size of the starting powder being only $2.21 \mu \mathrm{m}$. This grain growth is not representative of the bulk and likely due to local laser interaction with the material during processing. Furthermore, there is internal porosity within the WC grains, which is indicative of sintering mechanisms and high grain boundary mobility. As sintering generally occurs at about $60 \%$ of the melting temperature of the material $\left(2780^{\circ} \mathrm{C}\right.$ for $\left.\mathrm{WC}\right)$, this demonstrates that laser interaction with the material during manufacturing is enough to heat the powder bed to 


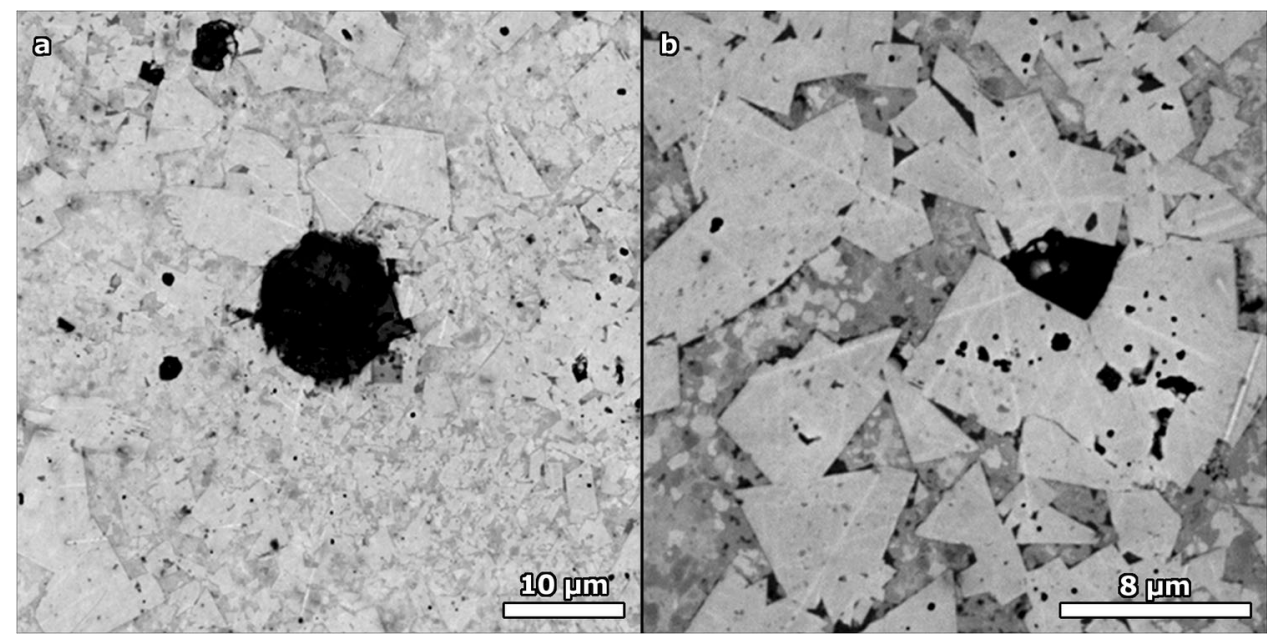

Fig. 4. Cross-section SEM images of sample 2 showing (a) circular porosity and (b) WC grains within the microstructure.

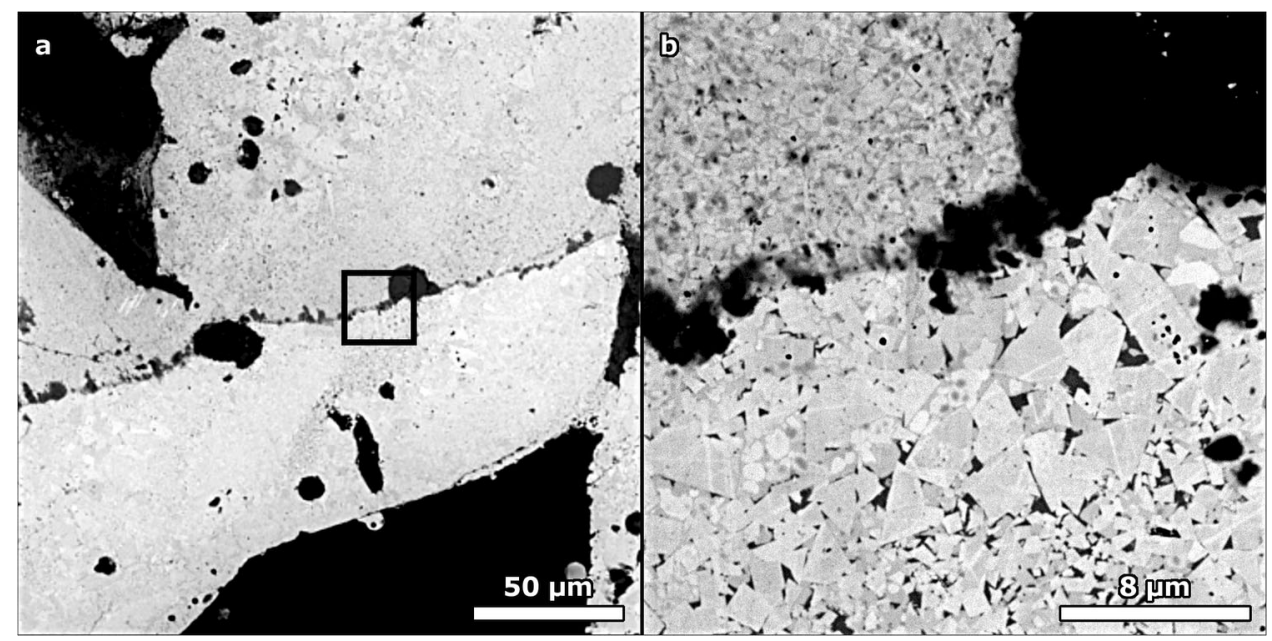

Fig. 5. Cross-section SEM images of sample 4 at (a) low magnification and (b) zoomed in to highlight evidence of layering in the microstructure.

highly elevated temperatures of at least $1660{ }^{\circ} \mathrm{C}$. Therefore, the powder bed temperature is much higher than the melting temperature of the binder, and lower laser energy densities may be functional to still effectively melt the binder and densify the material, thereby reducing thermal stresses and thermal cracking, reducing WC grain growth, and preventing the formation of internal pores within the WC grains of future samples.

A key challenge for any AM process is to reduce the artifacts of the layering process. Figure 5 shows the evidence of a layer in sample 4 , with a dark boundary line marking the layer. The darker boundary material may be due to a deposit of an oxide layer, which could suggest some contamination at the layer surface from an inadequately clean atmosphere. The argon gas used during manufacturing was not gettered and contains trace amounts of oxygen.

The small box in Fig. 5a highlights the area that is magnified and shown in Fig. 5b, which shows the difference in microstructure on either side of the boundary layer. On one side of the boundary is a very fine-grained microstructure with submicron grains, but the other side has a much coarser grain size. This may be due to the laser-powder interaction at the top of the layer being different from the interaction at the bottom of the layer, which again suggests that a lower laser energy density may be necessary.

\section{Post-HIPing}

Densities of the post-HIPed samples before and after the HIP process are shown in Table IV. Densities for all three parts increased after the HIP process. The data suggest that there is an inverse correlation between the laser energy density and the amount of increase in density from the HIP process. Due to higher energy densities yielding a higher part density from the print process, the reduced porosity before the HIP process limits the 
Table IV. The measured Archimedes' densities of the selected samples after hot isostatic pressing

\begin{tabular}{lccc}
\hline Sample & Energy density $\left(\mathbf{J} / \mathbf{m m}^{2}\right)$ & TD $(\%)$ after SLM & TD (\%) after HIP \\
\cline { 2 - 3 } & 8.89 & 91.4 & 94.4 \\
8 & 7.11 & 88.9 & 91.8 \\
14 & 3.56 & 77.6 & 96.1 \\
\hline
\end{tabular}

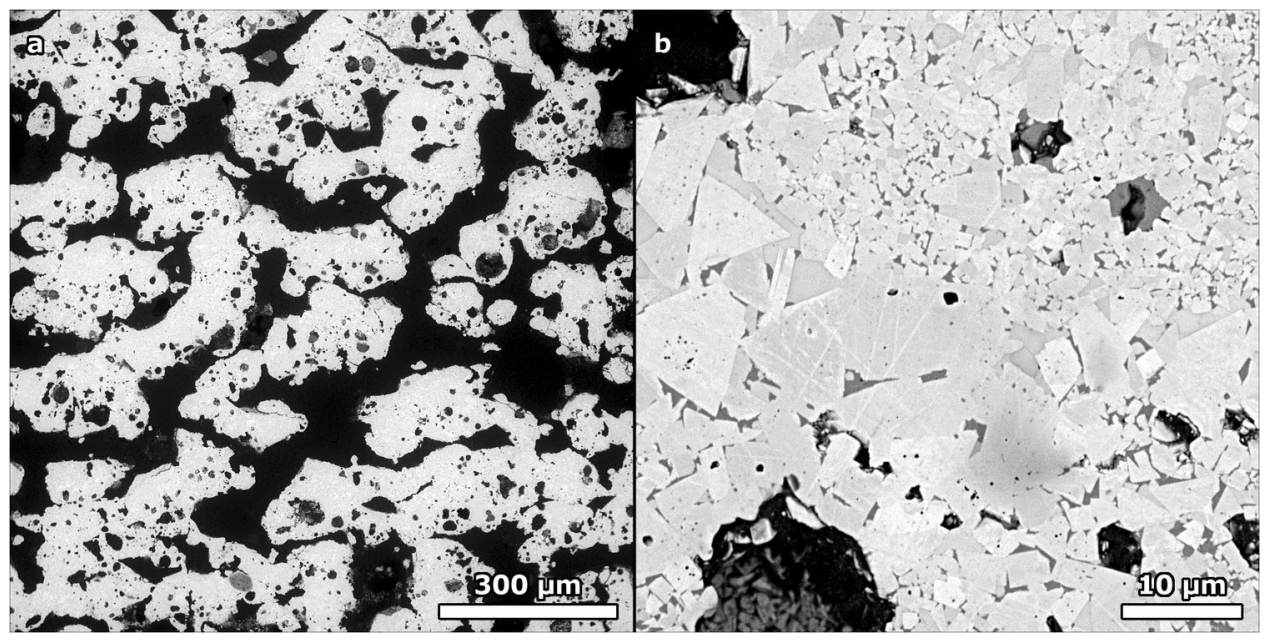

Fig. 6. Cross-section SEM images of sample 14 after HIP processing showing (a) macroscale and (b) microscale structures.

amount by which the density can be improved. Meanwhile, in an initially low density sample (e.g., sample 14), there is a large amount of starting porosity to allow for the most densification during the HIP process. The results demonstrate that subjecting printed samples to hot isostatic pressing as a post-process can effectively reduce porosity and further increase density.

While the measured theoretical densities of the samples, especially sample 14, are extremely promising, the measurement method used was water immersion by Archimedes' Principle. This means that macroscale open porosity is again excluded from the bulk volume. As shown in Fig. 6a, such large pores do exist in the sample, which means that the true bulk density is much lower than what is measured. Nevertheless, there is very dense material at the local level, with an ideal microstructure for a cemented carbide seen in the high-magnification image of sample 14 shown in Fig. $6 \mathrm{~b}$.

To understand the composition of the material and binder content in the cemented WC, semiquantitative XRF analysis was conducted, with the results listed in Table V. The instrument has a characteristic Zr peak, which convolutes any analysis of $\mathrm{Zr}$ content within the sample. As $\mathrm{Zr}$ is more refractory than $\mathrm{Fe}$ or $\mathrm{Ni}$, any binder loss due to vaporization would be evident in the two measured binder elements. Comparing the mass\% values of $\mathrm{Fe}$ and $\mathrm{Ni}$ in the SLM-processed samples to the raw
Table V. Semi-quantitative XRF analysis of WCFeNiZr powder and SLM processed samples by percent mass

\begin{tabular}{|c|c|c|c|}
\hline Element & WC & $\mathbf{F e}$ & $\mathbf{N i}$ \\
\hline Raw powder & 94.8 & 4.94 & 0.27 \\
\hline Sample 7 & 95.2 & 4.59 & 0.22 \\
\hline Sample 8 & 95.2 & 4.62 & 0.20 \\
\hline Sample 14 & 92.9 & 6.69 & 0.39 \\
\hline
\end{tabular}

powder shows no definitive evidence of loss of binder material, which implies that the relatively low laser power values used in this study may prevent the binder vaporization that was seen in the literature.

\section{CONCLUSION}

In this proof-of-concept study, samples of WC with 10 wt.\% Fe-Ni-Zr binder were printed using SLM. Even with the relatively low binder content, most of the samples possessed structural integrity, with theoretical skeletal densities as high as $95 \%$ with macroscale open porosity. The measured skeletal densities of the samples increased with increasing energy densities of the print. Microstructural analysis show very good wetting of the binder phase around the WC grains. Artifacts in the microstructure, such as WC grain growth, internal porosity 
within large WC grains, and thermal cracking, are evidence to suggest that the powder bed attained temperatures much higher than the melting temperature of the binder. Although the starting particle size was submicron, there were grains in the SLM-processed sample that had grown to several microns in size. These large grains were typically present in pocketed regions of the sample, while other areas exhibited more "ideal" microstructures, suggesting that further refinement of this technique could prove to be a suitable manufacturing method of cemented WC. Hot isostatic pressing of the selected samples further increased their density values. No evidence of binder vaporization was seen in the processed samples. The results from this study provide insight into the potential application of SLM to near-net-shape manufacture of highhardness cemented WC parts.

\section{ACKNOWLEDGEMENTS}

The authors would like to gratefully acknowledge Dr. Jeffery Swab, Dr. Brandon McWilliams, and Dr. Jian $\mathrm{Yu}$ for their technical advice and aid in equipment usage.

\section{OPEN ACCESS}

This article is distributed under the terms of the Creative Commons Attribution 4.0 International License (http://creativecommons.org/licenses/by/4.0/ ), which permits unrestricted use, distribution, and reproduction in any medium, provided you give appropriate credit to the original author(s) and the source, provide a link to the Creative Commons license, and indicate if changes were made.

\section{REFERENCES}

1. G.S. Upadhyaya, Cemented Tungsten Carbides: Production, Properties and Testing (Norwich, NY: Elsevier Science, 1998).

2. X. Zhang, Z. Guo, C. Chen, and W. Yang, Int. J. Refract. Met. Hard Mater. 70, 215 (2017). https://doi.org/10.1016/j.ijrmhm. 2017.10.005.
3. R.K. Enneti, K.C. Prough, T.A. Wolfe, A. Klein, N. Studley, and J.L. Trasorras, Int. J. Refract. Met. Hard Mater. 71, 28 (2018). https://doi.org/10.1016/j.ijrmhm.2017. 10.023 .

4. G.D. Rosen and B. Stucker, Additive Manufacturing Technologies: 3D Printing, Rapid Prototyping, and Direct Digital Manufacturing (New York, NY: Springer, 2014).

5. D.R. Lide, CRC Handbook of Chemistry and Physics, 84th ed. (Milton Park: Taylor \& Francis, 2003).

6. S. Kumar, J. Mater. Process. Technol. 209, 3840 (2009). https://doi.org/10.1016/j.jmatprotec.2008.08.037.

7. E. Uhlmann, A. Bergmann, and W. Gridin, Proc. CIRP 35, 8 (2015). https://doi.org/10.1016/j.procir.2015.08.060.

8. R.K. Enneti, K. Prough, A. Krishnan and S. Volk, Adv. Powder Metall. Part. Mater. 133 (2018).

9. C.-W. Li, K.-C. Chang, A.-C. Yeh, J.-W. Yeh, and S.-J. Lin, Int. J. Refract. Met. Hard Mater. 75, 225 (2018). https://doi. org/10.1016/j.ijrmhm.2018.05.001.

10. J. Cavaleiro, C.M. Fernandes, A.R. Farinha, C.V. Gestel, J. Jhabvala, E. Boillat, A.M.R. Senos, and M.T. Vieira, Appl. Surf. Sci. 427, 131 (2018). https://doi.org/10.1016/j.apsusc. 2017.08.039.

11. S. Kumar, J. Manuf. Process. 34, 121 (2018). https://doi.org/ 10.1016/j.jmapro.2018.05.036.

12. V. Richter and M.V. Ruthendorf, Int. J. Refract. Met. Hard Mater. 17, 141 (1999). https://doi.org/10.1016/s0263-4368(9 9)00003-7.

13. J. Tomas, Chem. Eng. Technol. 27, 605 (2004).

14. D. Schulze, Powders and Bulk Solids: Behavior, Characterization, Storage and Flow (Berlin: Springer, 2007).

15. National Toxicology Program, U.S. Department of Health and Human Services, 12, 115 (2011).

16. N. Tsurukawa, S. Prakash, and A. Manhart, Social impacts of artisanal cobalt mining in Katanga, Democratic Republic of Congo (Freiburg: Öko-Institut e.V, 2011).

17. J.J. Pittari, H.A. Murdoch, S.M. Kilczewski, B.C. Hornbuckle, J.J. Swab, K.A. Darling and J.C. Wright, Int. J. Refract. Met. Hard Mater. 76, (2018). https://doi.org/10.1016/ j.ijrmhm.2018.05.008.

18. J.J. Pittari, S.M. Kilczewski, J.J. Swab, K.A. Darling, H.A. Murdoch and B.C. Hornbuckle, Adv. Powder Metall. Part. Mater., 532-538 (2016).

19. G. Kasperovich, J. Haubrich, J. Gussone, and G. Requena, Mater. Des. 105, 160 (2016). https://doi.org/10.1016/j.matde s.2016.05.070.

Publisher's Note Springer Nature remains neutral with regard to jurisdictional claims in published maps and institutional affiliations. 